\title{
Developmental abnormalities of the optic nerve and chiasm
}

\begin{abstract}
Developmental anomalies of the optic nerve are an important and growing cause of lifelong visual handicap and they are often associated with systemic abnormalities. This review focuses on the ocular and systemic aspects of developmental anomalies arising from defects of fetal fissure closure and retinal ganglion cell development, and covers some other optic-disc anomalies that have systemic significance.

Eye (2007) 21, 1271-1284; doi:10.1038/sj.eye.6702851
\end{abstract}

Keywords: optic nerve hypoplasia; optic nerve aplasia; achiasmia; septo-optic dysplasia; foetal fissure; coloboma

\section{Introduction}

At least four in every 10000 children born in the UK will be diagnosed as severely visually impaired or blind (SVI/BL) by their first birthday, increasing to nearly six per 10000 by the age of 16 years. ${ }^{1}$

Paediatric ophthalmologists attend to several new cases each year, and it is a significant cause of blindness in childhood, ${ }^{1-5}$ possibly with an increasing incidence. ${ }^{6}$ Congenital optic nerve defects now account for about $15 \%$ of severe visual impairment or blindness in the UK: optic nerve hypoplasia $(\mathrm{ONH})$ alone accounting for $12 \%{ }^{1}$

As developmental abnormalities of the anterior visual pathways are often associated with brain, endocrine, and other systemic problems and syndromes, they may have far greater significance than to vision alone and many may be passed on to future generations.

Developmental abnormalities such as $\mathrm{ONH}$, in the early literature, were unusual. ${ }^{7}$ The expertise of early ophthalmoscopists, who were able to see retinal minutiae, such as Gunn's dots often not seen by today's practitioners with
D Taylor

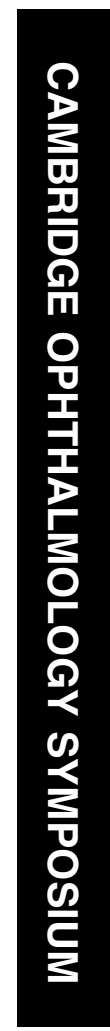

their technologically advanced kit, it seems unlikely that was overlooked as a diagnosis much more than it is today. $\mathrm{ONH}$ is thus probably both more common and better recognized than a few decades ago.

Imaging the developing visual system

Neuroimaging of the visual system in children with developmental anomalies of the optic nerve is a vital part of the overall assessment. ${ }^{8}$ The developing foetal and infant brain can be imaged by non-invasive ultrasound and by MRI; the former is less expensive but does not image the visual system very well. CT, employing ionizing radiation, is not used. MRI can be used clinically, at the moment, from 20 weeks and gives good images of all parts of the brain, with the added benefit of assessing myelination. At 23 weeks, the brain is agyric, except for the Sylvian fissures and the cortex is thin; myelination has not started. MRI evidence of myelination starts in the superior cerebellar peduncles, the medial longitudinal bundles, and the lemnisci at around 25-28 gestational weeks. ${ }^{9}$ By full-term birth, myelin is present in the cerebral white matter and in the first 4 months spreads to the internal capsule and the corpus callosum. The central occipital and frontal white matter become myelinated between 3 and 6 months and the peripheral a few months later (Table 1).

\section{Foetal fissure-related abnormalities}

\section{Coloboma}

A coloboma is a defect that results from an abnormality of the closure of the foetal fissure in the inferonasal quadrant of the developing optic cup. Closure starts at the equator and extends anteriorly and posteriorly: incomplete closure creates a defect of any size from the margin of the pupil to the optic disc, some are quite subtle.
Institute of Child Health, Visual Sciences Unit, London, UK

Correspondence: D Taylor Institute of Child Health, Visual Sciences Unit, 10 Guildford Street, London WC1N 1EH, UK Tel: + 0207 9357916; Fax: + 02073235430 E-mail: d.taylor@ ich.ucl.ac.uk

Received: 12 March 2007 Accepted in revised form: 3 April 2007 
Table 1 MRI images of the brain and visual system

\begin{tabular}{ll}
\hline Images visible of: & Post-conception age \\
\hline Cerebral vesicles & $35 / 7$ \\
Occipital pole & $43 / 7$ \\
Temporal pole & $50 / 7$ \\
Optic stalk/nerve & $7 / 40$ \\
Chiasm & $8-10 / 40$ \\
Eye visible as a cystic structure & $8-9 / 40$ \\
Lens & $10-12 / 40$ \\
Sylvian fissure & $16 / 40$ \\
PHPV seen & $20 / 40$ \\
Calcarine, parieto-occipital, and & $20-22 / 40$ \\
$\quad$ cingulate sulci & \\
Rolandic, interparietal, and & $25 / 40$ \\
$\quad$ superior temporal sulci & \\
Pre-central, post-central, superior & $24-28 / 40$ \\
$\quad$ frontal, and middle temporal sulci & \\
\hline
\end{tabular}

Microphthalmos and clinical anophthalmos may be extreme manifestations of the same disorder. Colobomas are unusual, occurring in about $0.25 \%$ of 12000 patients examined ophthalmoscopically.

Children with colobomas present either as a result of the appearance of the iris or of microphthalmos or, if bilateral, because of apparently poor vision or, if unilateral, with a squint. If a fundus coloboma is extensive, the parent may notice an abnormal red reflex on flash photography or a mother may notice it when feeding the baby with the light coning from behind her. Sometimes the systemic associations of colobomas are the presenting features or the coloboma may only be discovered on routine examination.

Typical optic disc colobomas are inferonasal and range from a hugely excavated disc to a subtle change in the retinal pigment epithelium (Figure 1). Colobomas of the disc may be associated with subtle manifestations of chorioretinal colobomas, iris or, rarely, inferonasal lens defects.

The subtle phenotypic expressions have the same diagnostic and genetic implications as gross manifestations.

Colobomas of the choroid create scotomas in proportion to their size and optic nerve colobomas may cause varying visual defects, depending on their size and the degree of macular involvement. Due to associated myopic astigmatism, amblyopia is often a significant factor.

\section{A classification}

Typical (inferonasal)

Iris

Choroid and retina

Optic disc and nerve

Optic nerve coloboma with cyst

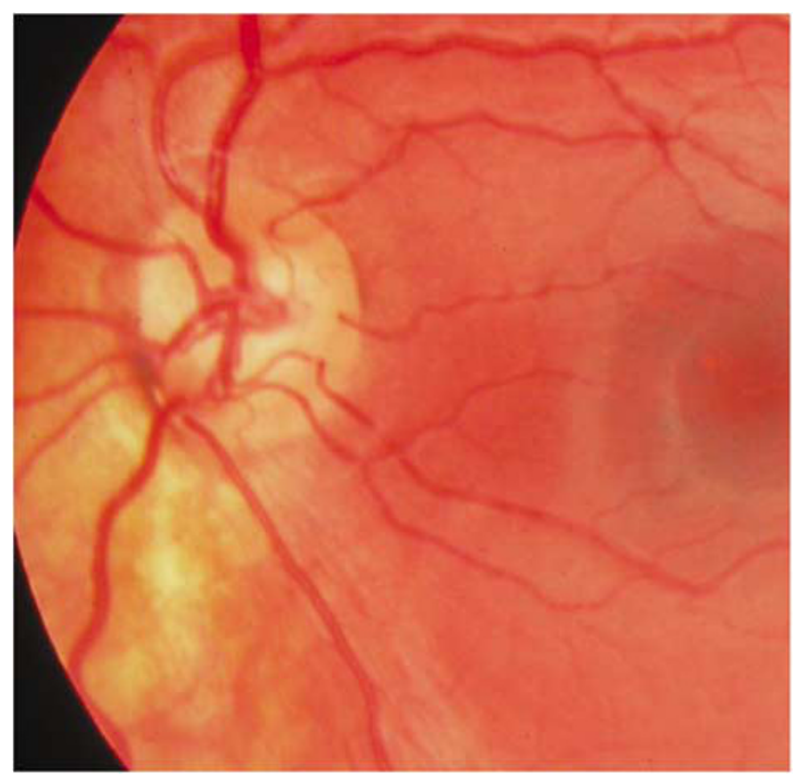

Figure 1 This left optic disc shows a tongue of relative pallor of the retinal pigment epithelium and choroid below and slightly nasal to it. The right eye had a marked coloboma in this child with the CHARGE association. Although functionally insignificant, this sign has as much diagnostic importance as a marked coloboma.

\section{Combinations of the above}

Atypical (other abnormalities not related to foetal fissure defects)

Many cases of coloboma without systemic associations are sporadic or dominantly inherited with variable expressivity. The parents and sibs of affected children should be examined for the sometimes subtle manifestations. Autosomal recessive inheritance is less frequent.

Various intraocular abnormalities may occur in association with colobomas: ${ }^{10}$ a preserved hyaloid vascular system, an anomalous Cloquet's canal, lens notches, vitreous striae, cataract, and glial tissue with dysplastic retina near the optic disc.

Heterotopic intraocular tissues, including lacrimal, cartilage with or without ossification, adipose, and smooth muscle sometimes occur. Smooth muscle, when present, may be the basis of periodic contraction of some colobomatous defects. ${ }^{11}$

When these tissues are present, the anomalies are sometimes known as Pedler's ${ }^{12}$ colobomas or 'coloboma of the optic disc with overlay of the peripapillary retina'. ${ }^{13}$ The scleral canal is large and the central nerve head is occupied by loose vascular connective tissue and the peripapillary retina was bunched up to three times the normal thickness and folded (Figure 2).

Colobomas may be associated with developmental cysts, which are presumably related foetal fissure closure 


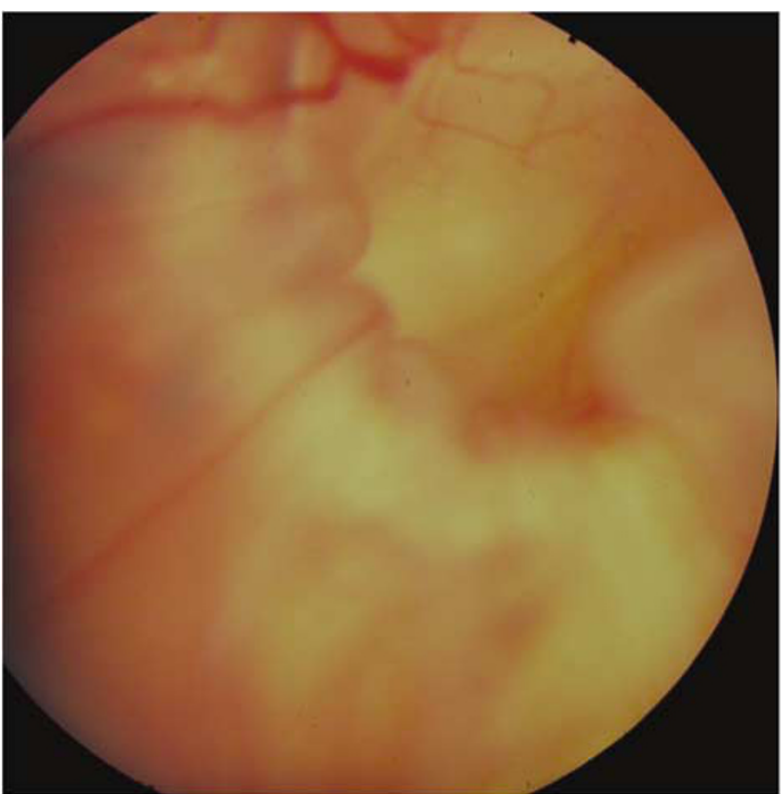

Figure 2 A 'Pedler' coloboma. There is a large central excavation and the peripapillary retina, and other tissues overlie the margins of the excavation. Some contain muscle which gives rise to periodic contractions.

defects. Orbital cysts with colobomas or colobomatous microphthalmos are unusual: they usually present first because of the ocular abnormality and the cyst presents because of its later enlargement. The cysts appear as a bluish swelling in the lower lid, which enlarges on crying or as a thin-walled cyst adjacent to the globe; it may cause a gradual proptosis and orbital enlargement. ${ }^{14}$ The cyst may communicate with the microphthalmic eye or be fused with it. ${ }^{14}$ Surgical decompression of the cyst may cause decompression of the eye and, if functionless, the microphthalmic eye may need to be removed. The benefit of leaving the cyst, if possible, is that it allows better orbital growth. Needle aspiration of the cyst (Figure 3) can cause a useful reduction in the size which can be permanent. ${ }^{15}$ The cysts contain cerebrospinal fluid and the wall may contain neuroglial tissue. ${ }^{16}$ The inheritance is similar to other colobomas; a large kinship was described in a consanguineous family. ${ }^{17}$

Neoplasms occurring along the line of closure of the foetal fissure are very rare: they include glioneuromas and medulloepitheliomas.

The presence of an optic disc coloboma should not blind the ophthalmologist to the presence of other eye malformations, in particular to glaucoma resulting from an anterior chamber anomaly, which may also cause disc excavation. Retinal detachment, subretinal neovascularization, and disciform degeneration may all occur as complications of colobomas of the choroid: their incidence is unknown, but they are probably rare, more frequent in severe colobomas. The retinal detachments are usually reported by retina units: incidence studies are difficult to conduct.

'Double' optic discs are usually a form of coloboma. ${ }^{18,19}$ The second optic disc usually lies below the main disc and has its own set of retinal vessels; it is often connected to the main disc by an arteriolar or a venular connection and a bridge of the coloboma.

Colobomas may occur either as part of a chromosomal syndrome or other systemic disease. The GENEYE database (www.lmdatabases.com) lists 80 syndromes associated with optic disc coloboma and 104 with iris coloboma, many overlapping. Such databases are vital to the systemic diagnosis and management of patients with colobomas as the systemic associations are so diverse - too diverse for all to be included in this article!

Chromosomal syndromes frequently associated with coloboma Trisomy 13 (Patau syndrome).

Cat-eye syndrome (trisomy or tetrasomy 22pter).

$4 \mathrm{p}$ - syndrome (Wolf-Hirschhorn syndrome).

Triploidy.

\section{Chromosomal syndromes uncommonly associated with coloboma}

Trisomy 18 (Edwards' syndrome).

Monosomy 9.

$11 q-, 13 q-$ trisomy $4 p$ and trisomy 22 .

The occurrence of colobomas with a systemic defect thus warrants chromosome studies.

\section{Coloboma as a part of a multisystem disorder}

\section{CHARGE association (Pagon's syndrome) CHARGE is a} mnemonic for coloboma, heart defect, atresia choanae, retarded growth and development, genital anomalies, and ear anomalies and deafness. ${ }^{20}$ A patient needs four of these major findings to fit the diagnosis. The other anomalies include facial palsy, micrognathia, cleft palate and pharyngeal incompetence, tracheo-oesophageal fistula, and renal anomalies.

Foetal fissure defects occur in most cases of the CHARGE association: they range from subtle (Figure 1) to microphthalmos. ${ }^{21}$

Lenz microphthalmia syndrome This is an X-linked condition with microphthalmos, microcephaly, vertebral, dental, renal and urogenital anomalies, congenital heart disease, protruding simple ears, and finger defects. The colobomas or colobomatous microphthalmos are variable and affected males have never reproduced, reducing familial recurrences. 


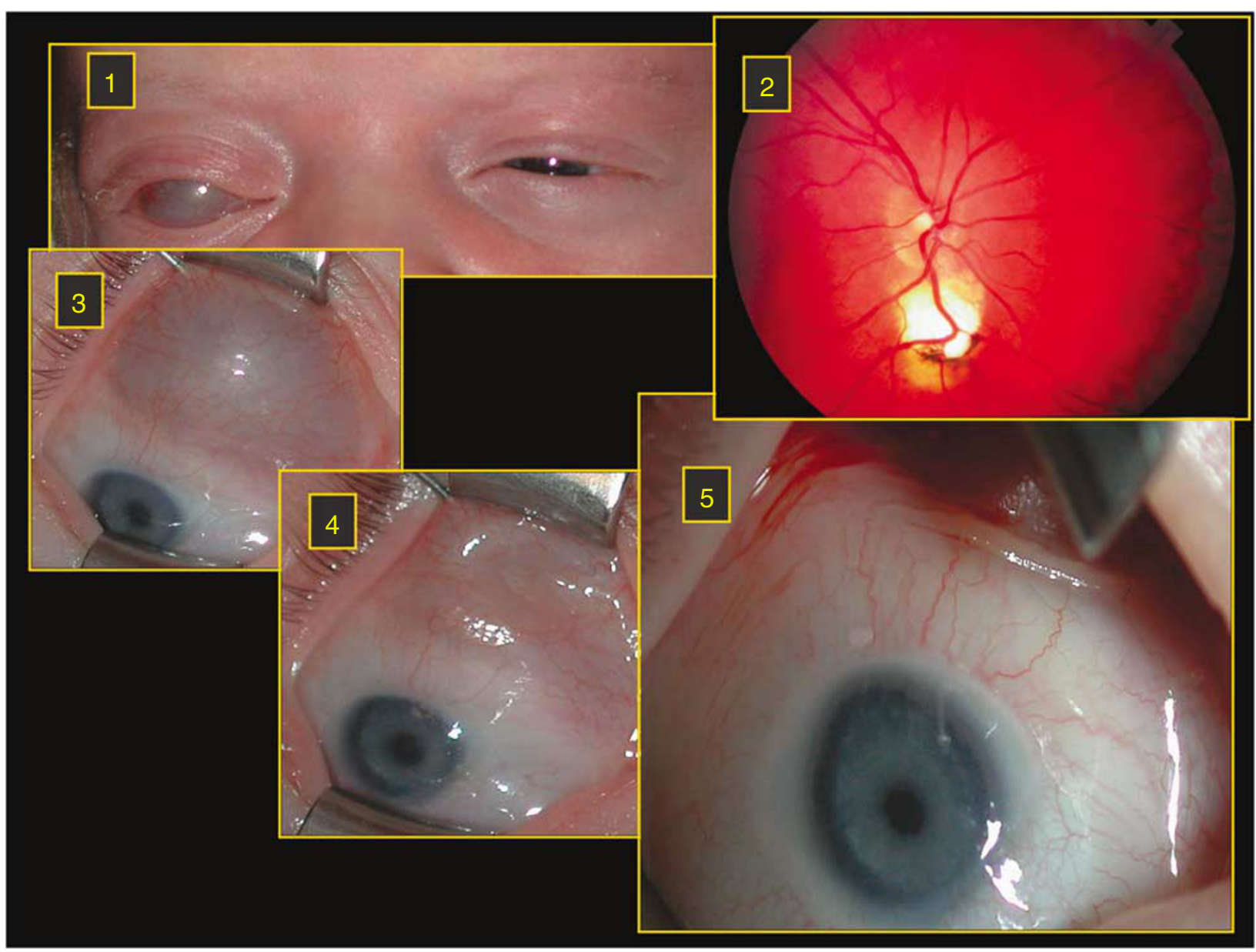

Figure 3 The right eye was microphthalmic and obscured by a large bluish cyst (1). The baby's mother had a small coloboma in her right eye (2). Repeated aspiration failed to cause a permanent reduction in the size of the cyst (3-5). ${ }^{15}$

Focal dermal hypoplasia (Goltz syndrome) The affected children are all born with focal dermal hypoplasia. Bony defects, dental anomalies, ocular findings, and mental retardation occur. Coloboma occurs with or without microphthalmos. The skin findings are striking, with pink atrophic macular areas, pinkish brown nodules of fat herniation through the dermis, and raspberry papillomas. Papillomas occur at skin-mucous membrane junctions, including the lids. It is thought to be X-linked dominant, lethal in males.

Meckel-Gruber syndrome This is a severe disorder of presumed autosomal recessive inheritance; affected infants usually have a very short lifespan. Findings include, in order of decreasing frequency, abnormal kidneys, occipital encephalocoele, polydactyly, cleft palate and micrognathia, abnormal urinary tracts, microphthalmia or coloboma, and congenital heart disease.

Joubert's syndrome These children often present in the first days of life with apnoea or tachypnoea, rhythmic tongue protrusions, and developmental delay. Mostly they have a retinal dystrophy, with relative preservation of the central vision and the visual defect is magnified by the frequent occurrence of a saccade initiation failure ('oculomotor apraxia') associated with hypoplasia of the cerebellar vermis. Up to a quarter have colobomas. ${ }^{22}$

Branchio-oculofacial syndrome The branchio-oculofacial syndrome is an autosomal dominant syndrome with variable expression. Patients have hypertrophy of the lateral pillars of the philtrum, which may look like a poorly repaired cleft lip, prominent and bilateral, vertical ridges between the lip and the nose, and aplastic or haemangiomatous cervical skin lesions, which may contain thymic tissue, with or without branchial sinuses. Malformed ears, cleft lip and palate, and colobomas with or without microphthalmos occur.

Basal cell naevus syndrome (Gorlin's syndrome) These children may present with macrocephaly, frontal and 
temporo-parietal bossing, and prominent supraorbital ridges prognathism, and telecanthus or hypertelorism. Multiple odontogenic keratocysts of the jaw develop during the first decade of life. These are multiple nevoid basal cell carcinomas that occur from late childhood, especially on the face and trunk. Colobomas may occur and myelinated retinal nerve fibres have been associated. Inheritance is autosomal dominant, with high penetrance and variable expression.

Coloboma associated with systemic anomalies of unknown aetiology

Linear naevus sebaceous syndrome This is also known as the epidermal naevus, Jadassohn's syndrome, Soloman's syndrome, or Fuerstein-Mimms syndrome. Affected children have a non-dermatomal linear pigmented naevus, a variety of other skin defects, skeletal anomalies, and usually severe developmental delay. Eye abnormalities include ptosis, epibulbar dermoids, and lid colobomas. Fundus abnormalities have been described, including colobomas, anomalous discs, peripapillary staphyloma, Coats' disease, pseudopapilloedema, osseous choristoma of the choroids, and $\mathrm{ONH}$.

\section{Coloboma with brain defects}

A variety of brain defects have been described together with coloboma: Dandy-Walker cyst, basal

encephalocoele, arrhinencephaly, and others

\section{Coloboma associated with teratogens}

Colobomas have occasionally been described in thalidomide, cocaine, and alcohol embryopathies.

\section{Optic disc pits}

These are greyish pits of variable size that usually occur temporally near the margin of the optic disc, although some may be central or nasal. They can be multiple and may be bilateral. They may be associated with visual field defects.

Optic disc pits may be of a similar pathogenesis to colobomas, but they often occupy a site unlikely to result from an abnormal closure of the foetal fissure, and they may occur with an optic disc coloboma either in the same eye or in the other eye.

Up to $60 \%$ of patients will develop central serous retinopathy with associated visual symptoms. The origin of subretinal fluid in humans with central serous retinopathy associated with a pit is still uncertain, but cerebrospinal fluid seems the most likely source. ${ }^{23}$ Although often following a benign course, subretinal neovascularization and other complications may occur, and some authors advocate aggressive treatment in selected cases such as vitrectomy, gas tamponade, and laser treatment. ${ }^{23}$

\section{Retinal ganglion cell axon-related abnormalities}

\section{Optic nerve aplasia}

Optic nerve aplasia is a very rare condition, which contributes little to the burden of child blindness. It was described shortly after the introduction of the ophthalmoscope. ${ }^{24}$ It is diagnosed in a blind eye, where there is no optic disc and no retinal vessels visible, but the occurrence of partial cases, cases with a few retinal blood vessels, or an area in the fundus that corresponds to an optic disc make it difficult to be dogmatic about inclusion. $^{25}$

From our cases, ${ }^{25}$ and from the literature, it appears that there may be three groups of cases:-

(1) Cases with a grossly normal choroid but no retinal vessels and no ophthalmoscopically visible optic disc. The ERG may be present but abnormal.

(2) Cases with a severely abnormal hyper-/ hypo-pigmented fundus, abnormal choroid, no retinal blood vessels, and no optic disc. The ERG is absent. Choroidal neovascularization is an occasional finding.

(3) Cases that have signs of foetal fissure closure defects (colobomas) but with no visible disc or an extremely abnormal disc. Retinal vessels may be present but are of abnormal origin and distribution. The ERG is present.

There have been a number of theories of aetiology and pathogenesis encompassing all stages and sites of development, without any unifying hypothesis, as one might expect for such a diverse condition, ${ }^{25}$ it may be due to ganglion cell development problems, but some cases (group 3) are related to abnormalities of the development of the foetal fissure or mesenchyme around the optic stalk (Table 2).

The literature is not clear as to the prevalence of systemic abnormalities in children with optic nerve aplasia: while unilateral cases are usually otherwise normal, bilateral cases may have associated brain, cardiac, and other abnormalities. There are 10 associated syndromes in the 'GENEYE' database www.lmdatabases.com. For cases without a family history or a history of consanguinity, the recurrence risks seem to be low.

\section{Optic nerve hypoplasia}

$\mathrm{ONH}$ is an abnormality of the optic disc that occurs before the complete development of the optic associated 
Table 2 Optic nerve aplasia

\begin{tabular}{|c|c|c|c|c|c|c|}
\hline & Optic disc & Retinal vessels & Choroid & $E R G$ & $V E P$ & Coloboma \\
\hline Group 1 & Not visible & Absent & Grossly normal & Present, abnormal & Absent & No \\
\hline Group 2 & Not visible & Absent & Severely abnormal & Absent & Absent & No \\
\hline Group 3 & $\begin{array}{l}\text { Not or barely } \\
\text { visible }\end{array}$ & Some present & Grossly normal & Present \pm normal & Severely abnormal & $\begin{array}{l}\text { Present in one } \\
\text { or both eyes }\end{array}$ \\
\hline
\end{tabular}

with a reduced population of retinal ganglion cell axons. It is a very significant cause of visual handicap in the developed world, being the cause of over $10 \%$ of severe visual impairment in childhood. ${ }^{1}$

Bilateral, severe, $\mathrm{ONH}$ presents as blindness in early infancy, with roving eye movements and sluggish or no pupil reactions to light. Lesser degrees of bilateral hypoplasia or unilateral hypoplasia may cause lesser visual defects or squint, or be found at a routine test. Amblyopia may contribute to the poor vision and the vision may improve with patching. ${ }^{8,26}$ Astigmatism may be frequent and affected patients may present because of a variety of endocrine disorders or brain defects. Hypoplastic discs occur more frequently in males than females, and probably without racial predilection. The parents of children with optic disc hypoplasia tend to be young, from poorer socio-economic groups, unemployed, ${ }^{27}$ and are smokers. ${ }^{5}$

Measurement of the optic disc size remains difficult, but some objectivity can be introduced by comparing ratios of vessel size and optic disc size or the disc-macula to disc diameter ratio. MRI may be better than photographic analysis when compared with clinical examination. The techniques of ultrasound,

photogrammetry, or optical coherence tomography may be helpful, but the diagnosis of $\mathrm{ONH}$ is not made on size alone: it is made on a combination of size, shape, an estimate of the number of axons, a small or absent cup, an increase in the tortuosity of the retinal vessels with fewer than normal branching points, ${ }^{28}$ and the presence of peripapillary abnormalities.

The area of the optic disc (outer ring) is composed of bare sclera or cribriform plate; this is variably larger than the circular area (inner ring) of the retinal nerve fibres (the optic disc 'substance'), known as the 'double ring' sign; this sign is, however, not pathognomonic of ONH.

There is a very wide variation in the appearance and effects of hypoplastic optic discs, all of which are best seen with high magnification, using a direct ophthalmoscope. Subtle outline changes, notches in a segment of the disc, and nerve fibre layer defects, associated with a relative smallness of the disc, may suggest the early onset of the problem, with severe $\mathrm{ONH}$ at one end of the spectrum and segmental hypoplasia or a tilted disc at the other. ${ }^{29,30}$
The optic disc substance may be a normal colour if the surviving nerve fibres are healthy and relatively numerous, but equally it may be pale, suggesting atrophy of the remaining fibres after the event that caused the hypoplasia. There seems to be a spectrum between the normal, atrophic, and hypoplastic discs that depends on how severe the causative event was and at which time or times it occurred. ${ }^{31}$

The visual effects are variable from good visual acuity (often with a field defect) to blindness. Visual acuity is determined largely by the size of the papillomacular bundle and not by the overall size of the disc, and the final vision may to some extent be predicted from assessment of the optic disc size, the initial acuity card assessment, and VEPs. ${ }^{32}$ Delayed visual maturation is not uncommon and it is best not to be too pessimistic after examinations in the early months. ${ }^{32}$ Refraction, visual acuity, colour vision, and visual fields are mandatory studies in older children and flash and pattern VEPs at all ages.

Children with periventricular leucomalacia (PVL) may have optic discs that are of normal overall size but may fall within a broad definition of hypoplastia by transsynaptic degeneration causing cupping. ${ }^{33,34}$ Acuity may be normal despite quite large cups and field defects, ${ }^{35}$ but may still cause concern about the possibility of glaucoma. However, the history of prematurity, the nonglaucomatous fields (where field studies are available) and the round cup, eccentric towards the temporal or supero-temporal parts of the optic disc, and the normal intraocular pressure, should be enough to distinguish this from glaucoma.

Timing The timing of any 'insult' must be after about 30 days when the retinal ganglion cell precursors appear and suggests the defect, when severe, occurs early in prenatal development. The development of the optic disc continues after birth, albeit at a much reduced rate, and some cases occur from an insult in late in pregnancy and even postnatally. ${ }^{33,34,36}$ Very hypoplastic discs probably result from an early insult and subtle hypoplasia, where the optic disc size is overall roughly normal, from later insult. 
Site Specific patterns of hypoplasia result from local defects throughout the central nervous system; ${ }^{37}$ the site of the 'insult' in $\mathrm{ONH}$ is reflected in the pattern of disc hypoplasia. Optic disc hypoplasia results from an early injury at any site in the developing nervous system.

Causes Optic disc hypoplasia is therefore probably a nonspecific abnormality resulting from an insult to any part of the visual system at an early stage of development.

$\mathrm{ONH}$ or tilted discs may be associated with a developmental tumour, particularly an optic glioma, in the region of the chiasm. ${ }^{25}$

There is a causal association with a wide variety of brain malformations, probably of common origin. Quinine, anticonvulsants, serotonin reuptake inhibitors, LSD and crack cocaine and, particularly, maternal alcohol ingestion and maternal diabetes have all been implicated as teratogens. ${ }^{25}$ Retro-chiasmal lesions may give rise to a pattern of $\mathrm{ONH}$ by trans-synaptic degeneration across the lateral geniculate body, which gives rise to a characteristic pattern of optic disc hypoplasia, 'homonymous hemioptic hypoplasia'. ${ }^{38}$ Typically the patient has a congenital hemianopia; on the side of the hemianopia, the optic disc is somewhat small and may lack fibres in the horizontal 'bow tie' band hypoplasia (Figure 4). The intact fibres subserving the intact nasal field are superior and inferior; the temporal field fibres are inserted all round the optic disc.

In about $10 \%$ of children (particularly premature females of low birth weight) of diabetic mothers with poor control, the superior half of the disc may be hypoplastic, the so-called superior segmental $\mathrm{ONH}^{39}$ or 'topless' optic discs (Figure 5). The visual defect is often
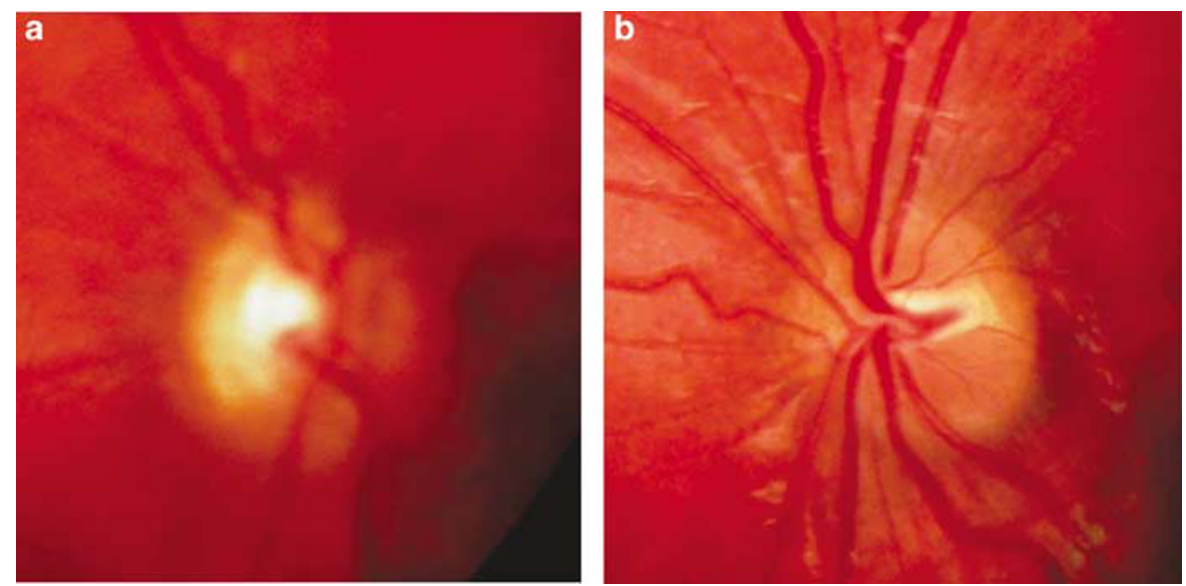

Figure 4 Band hypoplasia in a patient with achiasmia. (a) Right eye, defocused, showing severe ONH. (b) Left eye showing marked band hypoplasia. The retinal ganglion cell fibres that subserve the intact nasal field are intact; the temporal fibres are congenitally absent, giving the horizontal band of hypoplasia.
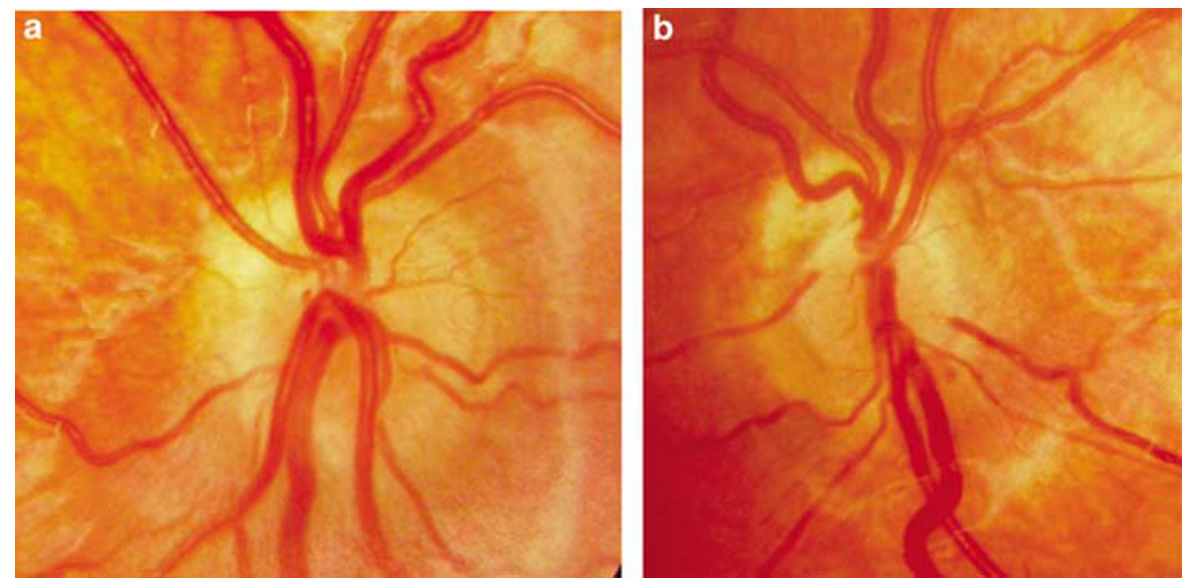

Figure 5 Child of a mother with severe diabetes. (a) Right eye and (b) left eye. The top half of both optic discs is hypoplastic ('superior segmental hypoplasia'). There is also macular hypoplasia. 
relatively mild. Topless discs may occur without maternal diabetes.

Family history and genetics Familial cases are rare and not all necessarily genetic, and in the absence of a recurrent environmental cause (such as drugs or alcohol) or a family history or consanguinity, a very low recurrence risk can be given. HESX1 mutations have been recorded ${ }^{40}$ but seem quite unusual. ${ }^{41}$

Septo-optic dysplasia Although the term septo-optic dysplasia implies absence of the septum pellucidum and $\mathrm{ONH}$ only, the syndrome encompasses a wide variety of structural abnormalities of the cerebral hemispheres and commisures, hypothalamus, visual system, the pituitary body, and stalk. Hemispheric abnormalities occur in nearly half of patients with $\mathrm{ONH}$, including migration anomalies (polymicrogyria, schizencephaly, heterotopia), intrauterine, or perinatal hemispheric injury (periventricular leukomalacia, encephalomalacia). ${ }^{42}$ In holoprosencephaly, a variable midline facial defect is associated with a single cerebral ventricle, and absence of the corpus callosum and septum pellucidum; there is also a wide variety of other brain defects causing similar problems.

Normally, the posterior pituitary gland appears bright on TI-weighted images, but in posterior pituitary ectopia, there is absence of the normal posterior pituitary and it's infundibulum, and an ectopic posterior pituitary bright spot at the tuber cinereum. This suggests anterior pituitary hormone deficiency, whereas the cerebral hemispheric abnormalities and thinning or agenesis of the corpus callosum suggest neurodevelopmental deficits in both bilateral and unilateral cases: absence of the septum pellucidum alone is not endocrinologically significant, ${ }^{43}$ and if the septum pellucidum and the hypothalamic-pituitary axis are both normal, it is unlikely that there will be any endocrine disturbance. ${ }^{43}$

A variety of hormonal defects have been described, ranging from isolated growth hormone, adrenocorticotrophic or antidiuretic hormone deficiency to panhypopituitarism. Hypothyroidism may be the most common significant abnormality, but there is wide variation, and the possibility of minimal abnormalities in multiple hormones should be remembered. Whether or not MRI abnormalities are found, weight and height must be monitored annually, usually under the care of the endocrinologist or paediatrician.

Children with septo-optic dysplasia are at risk for sudden death from the combination of reduced anterior and posterior pituitary hormones and hypothalamic defects when exposed to stress especially in the form of hyperthermia or infection. ${ }^{44,45}$

\section{Miscellaneous optic disc abnormalities}

\section{Dysplastic optic discs}

The term 'dysplastic' might be applied to any disc, which has a congenital anomaly but does not fall within one of the clearly defined anomalies (coloboma, hypoplasia etc). It is better, for instance, to call the optic disc anomaly in the papillo-renal syndrome dysplastic rather than calling it a coloboma, which implies it is a foetal fissure-related anomaly, which it may well not be. Any number of abnormalities are given the euphonic name 'morning glory' discs when they do not fall strictly into that description.

\section{Tilted discs and situs inversus}

The 'tilted' optic disc anomaly occurs in less than $2 \%$ of the population: ${ }^{46}$ minor degrees are probably more common. The features include optic disc dysversion and/or torsion, an astigmatic refractive error, which may be corneal with the steepest corneal curve in the same axis as the tilt and the apparent length of the oval disc equivalent to amount of astigmatism ${ }^{47}$ (Figure 6). There may also be situs inversus of the retinal vessels, peripapillary atrophy (scleral or myopic crescent), inferonasal chorioretinal thinning and pigment accumulation, posterior staphyloma, and visual field

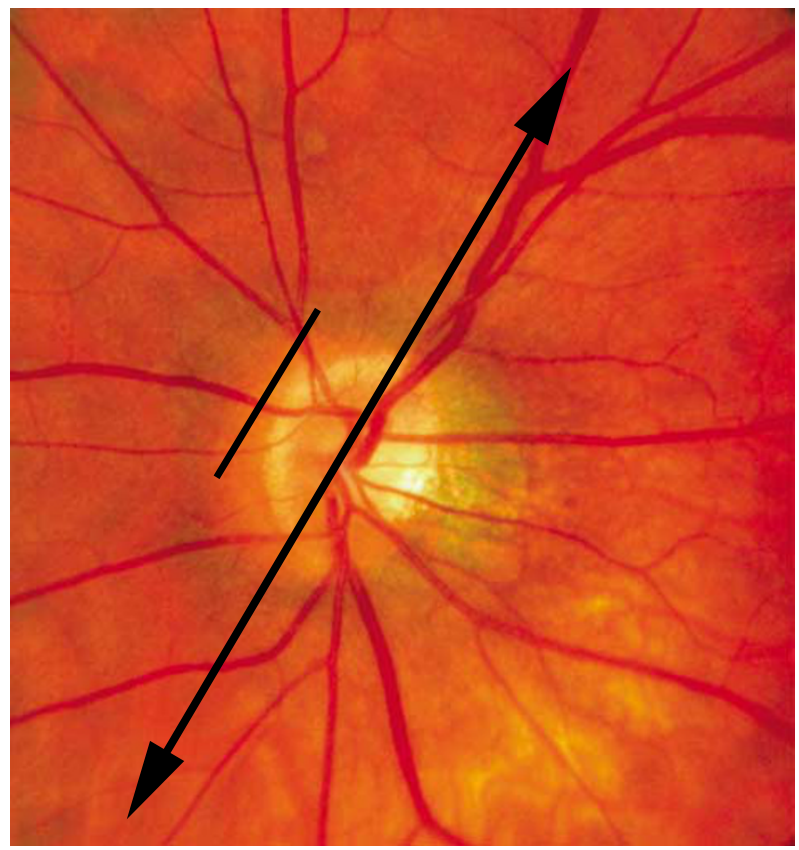

Figure 6 The double-headed arrow shows the axis if the astigmatism, which may be corneal. The bar, equivalent to the length of the optic disc, is related to the amount of astigmatism. $^{47}$ 
defects. ${ }^{46}$ The appearance of tilting is made evident by rotation of the superior pole of the disc, angulation of the optic cup axis inferonasally, and elevation of the supero-temporal neuroretinal rim. Situs inversus is a defect in which the vessels emerging from the (often small) optic disc are so distorted that, together with the appearance resulting from an associated tilt, the disc appears to be rotated through approximately $180^{\circ}$. There may be an associated posterior staphyloma below the disc. Non-progressive upper temporal relative visual field defects may occur, which cross the midline, but they usually largely disappear with optical correction or with larger test targets. Tilted discs may represent a minimal form of $\mathrm{ONH}^{29}$

\section{Morning glory anomaly}

This is an unusual defect, which is specific and the term should not be used loosely for other dysplastic optic discs. It was probably first described by Handemann ${ }^{48}$ and the term morning glory syndrome (after the flower) was coined by Kindler. ${ }^{49}$ The disc may be large and the peripapillary area is variably elevated with an associated annulus of pigment and there is a central glial tuft extending anteriorly to a variable extent. The vessels, which originate from near the disc edge, radiate outwards; it is often difficult to determine whether they are arterioles or venules, sometimes with $\mathrm{A}-\mathrm{V}$ communications ${ }^{50}$ adjacent to or distant from the disc.

The vision in the affected eye is usually, but not invariably, poor and may be worsened by amblyopia from myopic astigmatism (Figure 7). MRI studies show avariably excavated optic disc, ${ }^{51-53}$ with tissue in the excavation, which may be fat. ${ }^{52}$

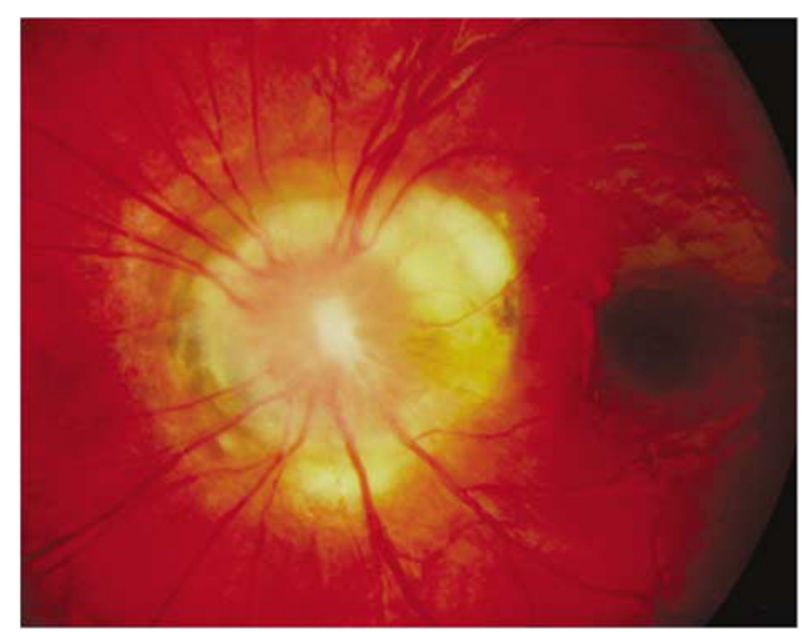

Figure 7 Morning Glory disc anomaly. The vision was unusually good (0.4 LogMAR) in this case with an intact macular, after occlusion treatment for anisometropic amblyopia.
Similar to some colobomatous and other defects, they may show slow contractile movements. ${ }^{54,55}$

There are three main systemic associations:

\section{(1) Basal encephalocoeles}

Basal encephalocoeles are associated with a variety of dysplastic discs, including typical ${ }^{53}$ Morning Glory anomaly; mostly, they are dysplastic, sometimes with features of colobomas, notably an inferior V-shaped chorioretinal pigment anomaly. ${ }^{56}$ The encephalocoele may present with difficulty feeding, mouth breathing, or snoring because of nasal obstruction, hypertelorism, or because of a midline notch in the upper lip or a cleft lip or palate.

\section{(2) Moyamoya disease}

The Morning Glory anomaly may be associated with (usually ipsilateral) cerebral vascular narrowing or closure, some may be associated with Moyamoya disease. ${ }^{57-59}$ Affected patients may present with strokes, transient ischaemic attacks (TIAs or mini-strokes), or epilepsy, and revascularization surgery may be successful in children.

\section{(3) PHACE syndrome}

A Morning Glory disc anomaly may, mostly in girls, be associated with an ipsilateral facial plaque-like haemangioma, ${ }^{60}$ meningeal involvement, ${ }^{61}$ posterior fossa malformations, cardiac malformations and aortic coarctation, and sternal clefting The visual prognosis is poor for the affected eye, which may also be amblyopic. ${ }^{62,63}$

Other associations ${ }^{53}$ include microtia, Duane's retraction syndrome, Brown's syndrome, cleft lip and palate, hypertelorism, agenesis of the corpus callosum, endocrine and central nervous system anomalies, and a variety of ocular defects. Not infrequently there is a widespread non-rhegmatogenous or rhegmatogenous ${ }^{64}$ retinal detachment, often early in life, which may settle spontaneously or with treatment.

Morning Glory disc is more common in girls; it is usually unilateral and non-genetic: its nosology and relationship to typical coloboma are uncertain. The association with Moyamoya disease and PHACES syndrome and the vascular features of the optic disc anomaly both suggest an abnormality of vasculogenesis, but the presence of an inferior tongue of depigmentation suggests a foetal fissure-related pathogenesis ${ }^{56}$ (Figure 8).

\section{Renal coloboma syndrome}

In this syndrome, optic disc excavation is central, with multiple cilioretinal vessels exiting the optic disc radially. ${ }^{65}$ Doppler ultrasound of the optic discs may 

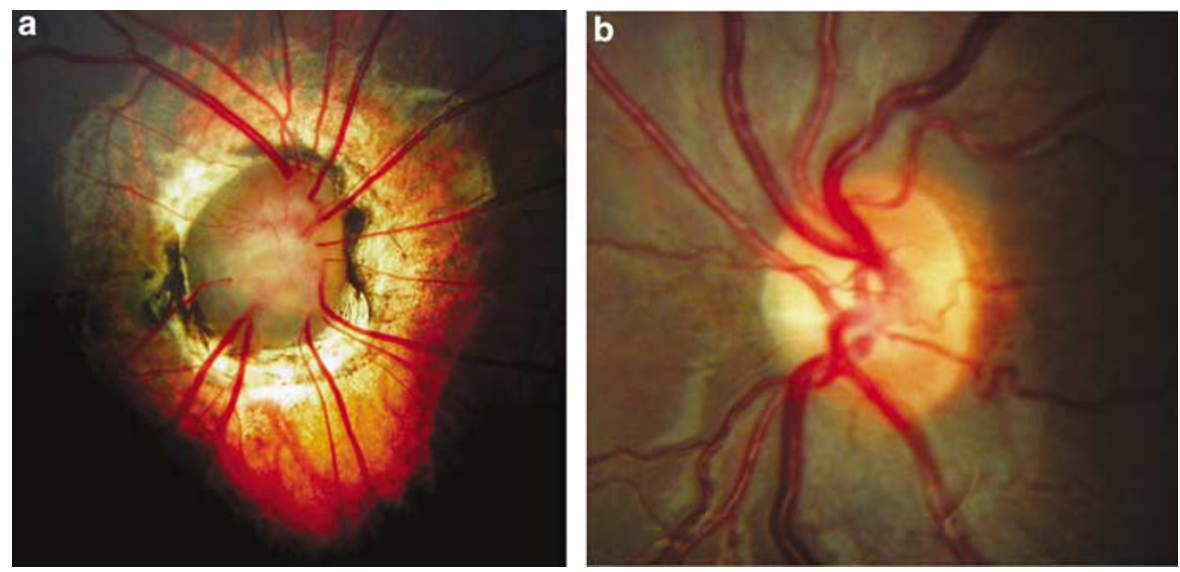

Figure 8 Optic disc anomalies in a patient with a sphenoidal encephalocoele. (a) Right eye showing a Morning Glory disc anomaly, with an inferior tongue of choroid and RPE depigmentation. (b) Left eye with band atrophy of the optic disc.
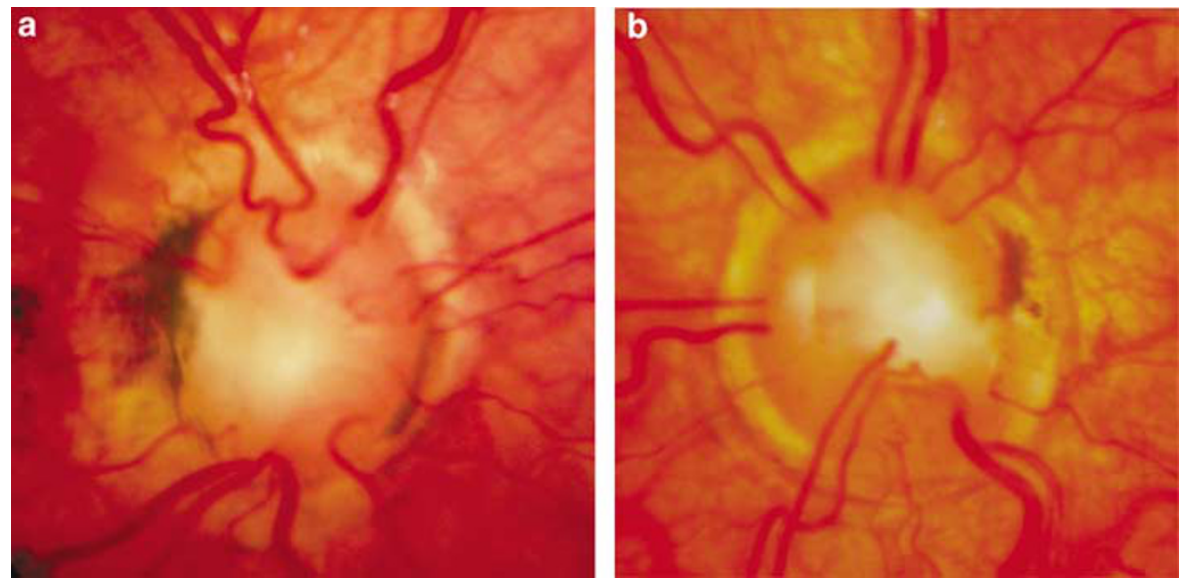

Figure 9 Papillorenal syndrome: dysplastic, 'vacant', optic discs with no vessels central in the optic disc. (a) Right eye and (b) left eye.

show reduced central retinal artery flow. Because there are no normal central vessels, the disc is excavated; it has been termed 'vacant' (Figure 9).

Patients with the syndrome may develop serous retinal detachments, perhaps associated with a pit, and they may have thin peripheral retinas.

Renal disease is variable and usually progressive, often necessitating renal transplantation for chronic renal failure in young adulthood. The diagnosis is usually made only when there is frank renal disease or a family history. The optic disc findings, however, are characteristic and can allow earlier diagnosis to limit renal morbidity. ${ }^{66}$ Some patients may have a PAX2 mutation. ${ }^{67}$

\section{Peripapillary staphyloma}

Peripapillary staphyloma is a non-hereditary congenital optic disc anomaly, in which a fundus excavation surrounds, locally, a relatively normal-appearing optic disc. ${ }^{68}$ It is generally unilateral and is also associated with poor vision including amblyopia.

Posterior staphyloma is a term used to describe the very variable ectasia of the posterior pole, centred on the macula, which is usually bilateral. It is not usually congenital and very strongly associated with progressive myopia.

In peripapillary staphyloma, the area of the sclera around the optic disc is ectatic and thus relatively myopic. There is often a certain amount of glial tissue in the disc, and the vessels radiate out from the edge of the disc. Occasionally a serous detachment of the retina around the disc occurs. Retinal detachment, choroidal neovascular membranes, and haemorrhages are not uncommon. Intermittent contraction ${ }^{69}$ suggests that some cases overlap with Pedler colobomas (above) and some are associated with midline encephalocoeles (see Morning Glory syndrome above).

The pathogenesis is unknown, but that it may sometimes be related to foetal fissure closure is attested 
by thinning of the choroid, usually inferior to the disc and the often inferior site of the staphyloma. Not all cases are below the disc, however, suggesting multiple aetiologies.

\section{Megalopapilla}

Megalopapilla is a generic term used for large optic discs without other significant abnormalities. The optic disc may also be large in, for instance, Morning Glory syndrome and peripapillary staphyloma or congenital glaucoma, but in those instances, the primary diagnosis is used to describe it. Many represent the extreme end of the normal range of optic disc size.

There seem to be two main phenotypes:- ${ }^{51}$

(1) A usually bilateral form with a basically normal configuration but an overall diameter of $2.1 \mathrm{~mm}$, a large round or horizontally oval cup, and associated with a normal rim volume without notches, a normal visual field (large blind spots), and a normal IOP. They may appear pale as the axons are spread over a larger than normal area of cribriform plate.

(2) A large disc (figure with an excavation that is non-colobomatous (does not occur in the inferonasal quadrant)). Cilioretinal arteries are common.

\section{Chiasmal maldevelopment}

\section{Achiasmia}

Whenever there is $\mathrm{ONH}$, there is some degree of chiasmal hypoplasia: normal proportions of retinal ganglion cell axons have been directed ipsilaterally and contralaterally, but, overall, are fewer in number. However, in achiasmia, the chiasm is not just hypoplastic: it has the essential absence or relative lack of the crossing fibres. For complete absence of the chiasm, the term 'chiasmal aplasia' is more appropriate

(Figure 10).

Absence of the human chiasm was first reported in recent times by Apkarian et al, ${ }^{70,71}$ coining the term 'non-decussating retinal-fugal fibre syndrome', NDRFFS.

Achiasmia is diagnosed on the finding of significant electrophysiological evidence of reduced decussation, confirmatory neuroimaging, and nystagmus (sometimes see-saw). They may also have developmental delay and optic disc anomalies. ${ }^{72}$

Three types have been suggested: ${ }^{72}$

1. Type A: reduced decussation, with basically normal appearing optic nerves on clinical examination. A small chiasm is the only abnormality on brain MRI scanning. This group appears to overlap with NDRFFS. There may be see-saw or purely horizontal nystagmus, and the visual fields appear to be normal. ${ }^{73}$

2. Type B: reduced decussation, with chiasmal hypoplasia and the midline defects of septo-optic dysplasia. $^{74}$

3. Type C: reduced decussation and chiasmal hypoplasia in association with clefts and encephalocoeles of the skull base. Agenesis of the corpus callosum is frequent.

Some cases defy classification within these groups.

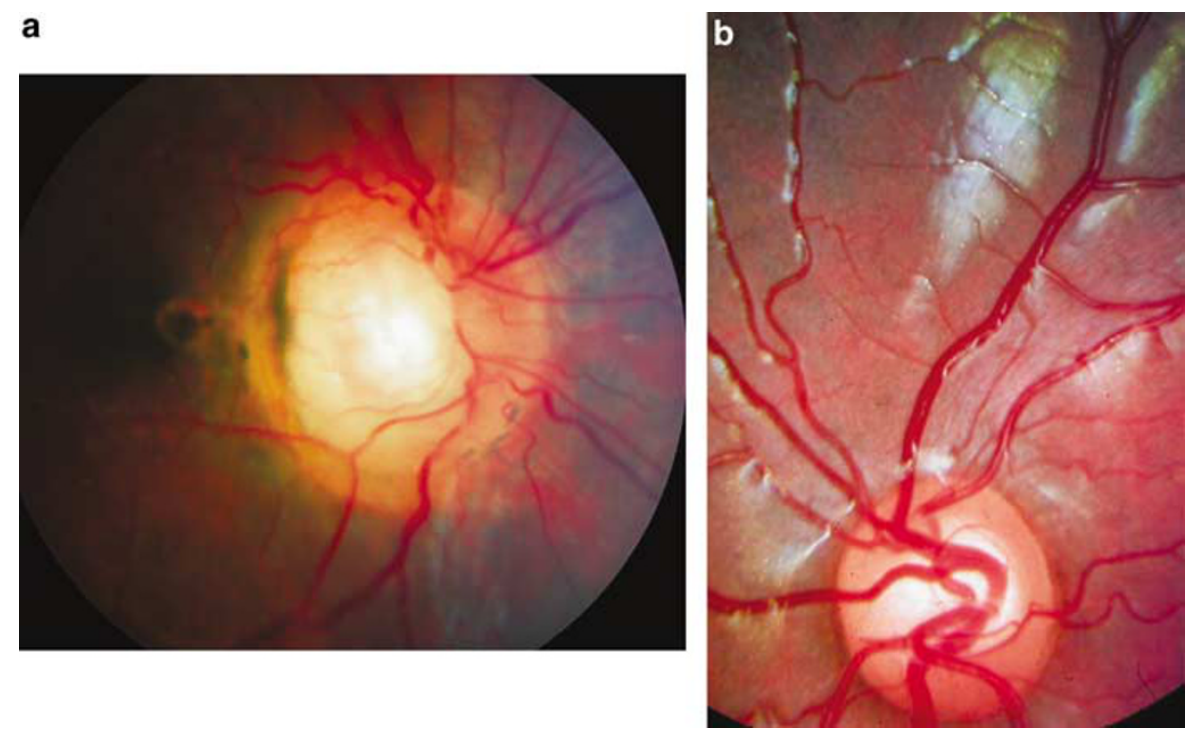

Figure 10 (a) Right eye megalopapilla with central excavation in an otherwise healthy child. Acuity less than 6/60. (b) Left eye with central cupping. Incidentally, Gunn's dots can be seen nasally and superior to the optic disc; they are seen in most children-if looked for! 
Although suspected on clinical grounds and strongly indicated by electrophysiology, MRI studies are the best way of confirming the diagnosis.

Achiasmic patients can have good, ${ }^{75}$ and sometimes remarkably normal, vision despite MRI- and fMRI-proven functional achiasmia. ${ }^{76}$

\section{Maldevelopment of the optic tracts}

Tract abnormalities may cause $14 \%$ of homonymous hemianopias in childhood, ${ }^{77}$ but the majority of these are probably acquired. The tracts may be absent in association with optic nerve aplasia ${ }^{78}$ Absence of the optic tracts on MRI studies may be associated with ipsilateral band atrophy and contralateral pallor, and with other visual system and cerebral abnormalities. ${ }^{79,80}$

\section{References}

1 Rahi JS, Cable N. Severe visual impairment and blindness in children in the UK. Lancet 2003; 362: 1359-1365.

2 Blohme J, Tornqvist K. Visual impairment in Swedish children. II. Etiological factors. Acta Ophthalmol Scand 1997; 75: 199-205.

3 Blohme J, Tornqvist K. Visual impairment in Swedish children. I. Register and prevalence data. Acta Ophthalmol Scand 1997; 75: 194-198.

4 Blohme J, Tornqvist K. Visual impairment in Swedish children. III. Diagnoses. Acta Ophthalmol Scand 1997; 75: 681-687.

5 Tornqvist K, Ericsson A, Kallen B. Optic nerve hypoplasia: risk factors and epidemiology. Acta Ophthalmol Scand 2002; 80: 300-304.

6 Jan JE, Robinson GC, Kinnis C, MacLeod PJ. Blindness due to optic-nerve atrophy and hypoplasia in children: an epidemiological study (1944-1974). Dev Med Child Neurol 1977; 19: 353-363.

7 Reeves C, Taylor D. A history of the optic nerve and its diseases. Eye 2004; 18: 1096-1109.

8 Kim MR, Park SE, Oh SY. Clinical feature analysis of congenital optic nerve abnormalities. Jpn J Ophthalmol 2006; 50: 250-255.

9 Barkovich AJ, Kjos BO, Jackson Jr DE, Norman D. Normal maturation of the neonatal and infant brain: MR imaging at 1.5 T. Radiology 1988; 166: 173-180.

10 Taylor D, Stout A In: Taylor DSI (ed). Paediatric Ophthalmology, 2nd edn. Blackwell Science: Oxford, 1997, pp 660-700.

11 Foster JA, Lam S. Contractile optic disc coloboma. Arch Ophthalmol 1991; 109: 472-473.

12 Pedler C. An unusual coloboma of the optic nerve entrance. Br J Ophthalmol 1961; 45: 803-808.

13 Cogan DG. Coloboma of the optic nerve with overlay of the peripapillary retina. Br J Ophthalmol 1978; 62: 347-350.

14 Altun E, Aribal E, Toker E, Ogut MS. Anterior coloboma with macrophthalmos and cyst: MR findings. Clin Imaging 2005; 29: 430-433.

15 Raynor M, Hodgkins PR. Microphthalmos with cyst - preservation of the eye by repeated aspiration. J Pediatr Ophthalmol Strabismus 2001; 38: 245-246.
16 Garcia LM, Castro E, Foster JA, Green RW, Traboulsi EI. Colobomatous microphthalmia and orbital neuroglial cyst: case report. Ophthalmic Genet 2002; 23: 37-42.

17 Porges Y, Gershoni-Baruch R, Leibu R, Goldscher D, Zonis S, Shapira I. Hereditary microphthalmia with colobomatous cyst. Am J Ophthalmol 1992; 114: 30-34.

18 Islam N, Best J, Mehta JS, Sivakumar S, Plant GT, Hoyt WF. Optic disc duplication or coloboma? Br J Ophthalmol 2005; 89: 26-29.

19 McLoone EM, Buchanan TA. Duplication of the optic disc: true or pseudo? A coloboma or not a coloboma? Eur J Ophthalmol 2004; 14: 163-165.

20 Pagon RA, Graham Jr JM, Zonana J, Yong SL. Coloboma, congenital heart disease, and choanal atresia with multiple anomalies: CHARGE association. J Pediatr 1981; 99: 223-227.

21 Russell-Eggitt IM, Blake KD, Taylor DS, Wyse RK. The eye in the CHARGE association. Br J Ophthalmol 1990; 74: 421-426.

22 Hodgkins PR, Harris CM, Shawkat FS, Thompson DA, Chong K, Timms C et al. Joubert syndrome: long-term follow-up. Dev Med Child Neurol 2004; 46: 694-699.

23 Poulson AV, Snead DR, Jacobs PM, Ahmad N, Snead MP. Intraocular surgery for optic nerve disorders. Eye 2004; 18: 1056-1065.

24 Newman W. Congenital blindness in two sisters-absence of optic disc and retinal vessels. Royal Lond Ophthalm Hosp Rep 1864; 6: 202-204.

25 Taylor D. Optic nerve axons: life and death before birth. Eye 2005; 19: 499-527.

26 Kushner BJ. Functional amblyopia associated with abnormalities of the optic nerve. Arch Ophthalmol 1984; 102: 683-685.

27 Patel L, McNally RJ, Harrison E, Lloyd IC, Clayton PE. Geographical distribution of optic nerve hypoplasia and septo-optic dysplasia in Northwest England. J Pediatr 2006; 148: 85-88.

28 Hellstrom A, Wiklund LM, Svensson E. The clinical and morphologic spectrum of optic nerve hypoplasia. J AAPOS 1999; 3: 212-220.

29 Dorrell D. The tilted disc. Br J Ophthalmol 1978; 62: 16-20.

30 Frisen L, Holmegaard L. Spectrum of optic nerve hypoplasia. Br J Ophthalmol 1978; 62: 7-15.

31 Hoyt CS, Good WV. Do we really understand the difference between optic nerve hypoplasia and atrophy? Eye 1992; 6(Part 2): 201-204.

32 Weiss AH, Kelly JP. Acuity, ophthalmoscopy, and visually evoked potentials in the prediction of visual outcome in infants with bilateral optic nerve hypoplasia. J AAPOS 2003; 7: 108-115.

33 Jacobson L, Hellstrom A, Flodmark O. Large cups in normal-sized optic discs: a variant of optic nerve hypoplasia in children with periventricular leukomalacia. Arch Ophthalmol 1997; 115: 1263-1269.

34 Hellström A. Optic nerve morphology may reveal adverse events during prenatal and perinatal life-digital image analysis. Surv Ophthalmol 2000; 44: S63-S73.

35 Brodsky MC. Periventricular leucomalacia. An intracranial cause of pseudoglaucomatous cupping. Arch Ophthalmol 2001; 119: 626-627.

36 Frisen L, Holmegaard L. Spectrum of optic nerve hypoplasia. Br J Ophthalmol 1978; 62: 7-15.

37 Novakovic P, Taylor DSI, Hoyt WF. Localising patterns of optic nerve hypoplasia - retina to occipital lobe. $\mathrm{Br} J$ Ophthalmol 1988; 72: 176-183. 
38 Hoyt WF, Rios-Montenegros EN, Berens MM, Eckelhoff RJ. Homonymous hemioptic hypoplasia. Fundoscopic features in standard and red-free illumination in three patients with congenital hemiplegia. Br J Ophthalmol 1972; 56: 537-545.

39 Kim RY, Hoyt WF, Lessel S, Narahara NH. Superior segmental optic hypoplasia: a sign of maternal diabetes. Arch Ophthalmol 1989; 107: 1312-1315.

40 Dattani MT, Martinez-Barbera JP, Thomas PQ, Brickman JM, Gupta R, Martensson IL et al. Mutations in the homeobox gene HESX1/Hesx1 associated with septo-optic dysplasia in human and mouse. Nat Genet 1998; 19: 125-133.

41 Polizzi A, Pavone P, Iannetti P, Manfre L, Ruggieri M et al. Septo-optic dysplasia complex: a heterogeneous malformation syndrome. Pediatr Neurol 2006; 34: 66-71.

42 Brodsky M, Glasier C. Optic nerve hypoplasia: clinical significance of associated central nervous system abnormalities on magnetic resonance imaging. Arch Ophthalmol 1993; 111: 66-74.

43 Birkebaek NH, Patel L, Wright NB, Grigg JR, Sinha S, Hall CM. Optic nerve size evaluated by magnetic resonance imaging in children with optic nerve hypoplasia, multiple pituitary hormone deficiency, isolated growth hormone deficiency, and idiopathic short stature. J Pediatr 2004; 145: 536-541.

44 Brodsky MC, Conte FA, Taylor D, Hoyt CS, Mrak RE. Sudden death in septo-optic dysplasia. Report of 5 cases. Arch Ophthalmol 1997; 115: 66-70.

45 Donahue SP, Lavina A, Najjar J. Infantile infection and diabetes insipidus in children with optic nerve hypoplasia. Br J Ophthalmol 2005; 89: 1275-1277.

46 Vongphanit J, Mitchell P, Wang JJ. Population prevalence of tilted optic disks and the relationship of this sign to refractive error. Am J Ophthalmol 2002; 133: 679-685.

47 Jonas JB, Kling F, Grundler AE. Optic disc shape, corneal astigmatism, and amblyopia. Ophthalmology 1997; 104: 1934-1937.

48 Handemann M. Erbliche, vermutlich angenborene zentrale gliose Entartung des Sehnerven mit besonderer. Beteilgung der Zentral-gefasse. Klin Mbl Augenheilkd 1929; 83: 145-154.

49 Kindler P. Morning glory syndrome: unusual congenital optic disk anomaly. Am J Ophthalmol 1970; 69: 376-384.

50 Brodsky MC, Wilson RS. Retinal arteriovenous communications in the morning glory disc anomaly. Arch Ophthalmol 1995; 113: 410-411.

51 Brodsky MC In: Taylor D, Hoyt C (eds). Paediatric Ophthalmology and Strabismus, 3 edn. Elsevier Saunders: London, 2005, pp 625-645.

52 Auber AE, O'Hara M. Morning glory syndrome. MR imaging. Clin Imaging 1999; 23: 152-158.

53 Chen CS, David D, Hanieh A. Morning glory syndrome and basal encephalocele. Childs Nerv Syst 2004; 20: 87-90.

54 Chuman H, Nao-i N, Sawada A. [A case of morning glory syndrome associated with contractile movement of the optic disc and subretinal neovascularization]. Nippon Ganka Gakkai Zasshi 1996; 100: 705-709.

55 Pollock S. The morning glory disc anomaly: contractile movement, classification, and embryogenesis. Doc Ophthalmol 1987; 65: 439-460.

56 Brodsky MC, Hoyt WF, Hoyt CS, Miller NR, Lam BL. Atypical retinochoroidal coloboma in patients with dysplastic optic discs and transsphenoidal encephalocele. Arch Ophthalmol 1995; 113: 624-628.

57 Bakri SJ, Siker D, Masaryk T, Luciano MG, Traboulsi EI. Ocular malformations, moyamoya disease, and midline cranial defects: a distinct syndrome. Am J Ophthalmol 1999; 127: 356-357.

58 Massaro M, Thorarensen O, Liu GT, Maguire AM, Zimmerman RA, Brodsky MC. Morning glory disc anomaly and moyamoya vessels. Arch Ophthalmol 1998; 116: 253-254.

59 Murphy MA, Perlman EM, Rogg JM, Easton JD, Schuman JS. Reversible carotid artery narrowing in morning glory disc anomaly. J Neuroophthalmol 2005; 25: 198-201.

60 Holmstrom G, Taylor D. Capillary haemangiomas in association with morning glory disc anomaly. Acta Ophthalmol Scand 1998; 76: 613-616.

61 Ioannidis AS, Liasis A, Syed S, Harper J, Nischal KK. The value of visual evoked potentials in the evaluation of periorbital hemangiomas. Am J Ophthalmol 2005; 140: 314-316.

62 Schwartz SR, Blei F, Ceisler E, Steele M, Furlan L, Kodsi S. Risk factors for amblyopia in children with capillary hemangiomas of the eyelids and orbit. J AAPOS 2006; 10: 262-268.

63 Kronenberg A, Blei F, Ceisler E, Steele M, Furlan L, Kodsi S. Ocular and systemic manifestations of PHACES (posterior fossa malformations, hemangiomas, arterial anomalies, cardiac defects and coarctation of the aorta, eye abnormalities, and sternal abnormalities or ventral developmental defects) syndrome. J AAPOS 2005; 9: 169-173.

64 Yamakiri K, Uemura A, Sakamoto T. Retinal detachment caused by a slitlike break within the excavated disc in morning glory syndrome. Retina 2004; 24: 652-653.

65 Parsa CF, Goldberg MF, Hunter DG. Papillorenal ('renal coloboma') syndrome. Am J Ophthalmol 2002; 134: 300-301.

66 Khan AO, Nowilaty SR. Early diagnosis of the papillorenal syndrome by optic disc morphology. J Neuroophthalmol 2005; 25: 209-211.

67 Fletcher J, Hu M, Berman Y, Collins F, Grigg J, McIver M. Multicystic dysplastic kidney and variable phenotype in a family with a novel deletion mutation of PAX2. J Am Soc Nephrol 2005; 16: 2754-2761.

68 Kim SH, Choi MY, Yu YS, Huh JW. Peripapillary staphyloma: clinical features and visual outcome in 19 cases. Arch Ophthalmol 2005; 123: 1371-1376.

69 Farah ME, Uno F, Bonomo PP, Nóbrega M, Höfling-Lima A. Contractile peripapillary staphyloma with light stimulus to the contralateral eye. Arch Ophthalmol 2001; 119: 1216-1217.

70 Apkarian P, Bour L, Barth PG. A unique achiasmatic anomaly detected in non-albinos with misrouted retinal-fugal projections. Eur J Neurosci 1994; 6: 501-507.

71 Apkarian P, Bour LJ, Barth PG, Wenniger-Prick L, Verbeeten B. Non-decussating retinal-fugal fibre syndrome. An inborn achiasmatic malformation associated with visuotopic misrouting, visual evoked potential ipsilateral asymmetry and nystagmus. Brain 1995; 118(Part 5): 11951216.

72 Sami DA, Saunders D, Thompson DA, Russell-Eggitt IM, Nischal KK, Jeffrey G et al. The achiasmia spectrum: congenitally reduced chiasmal decussation. $\mathrm{Br} J$ Ophthalmol 2005; 89: 1311-1317.

73 Apkarian P, Bour LJ. See-saw nystagmus and congenital nystagmus identified in the non-decussating retinal-fugal fiber syndrome. Strabismus 2001; 9: 143-163.

74 Thompson DA, Kriss A, Chong K, Harris C, Russell-Eggitt I, Shawkat $\mathrm{F}$ et al. Visual-evoked potential evidence of chiasmal hypoplasia. Ophthalmology 1999; 106: 2354-2361. 
75 Thompson DA, Kriss A, Chong K, Harris C, Russell-Eggitt I, Shawkat $\mathrm{F}$ et al. Visual-evoked potential evidence of chiasmal hypoplasia. Ophthalmology 1999; 106: 2354-2361.

76 Victor JD, Apkarian P, Hirsch J, Conte MM, Packard M, Relkin NR et al. Visual function and brain organization in non-decussating retinal-fugal fibre syndrome. Cereb Cortex 2000; 10: 2-22

77 Kedar S, Zhang X, Lynn MJ, Newman NJ, Biousse V. Pediatric homonymous hemianopia. J AAPOS 2006; 10: 249-252.
78 Scott IU, Warman R, Altman N. Bilateral aplasia of the optic nerves, chiasm, and tracts in an otherwise healthy infant. Am J Ophthalmol 1997; 124: 409-410.

79 Margo CE, Hamed LM, McCarty J. Congenital optic tract syndrome. Arch Ophthalmol 1991; 109: 1120-1122.

80 Waheed K, Jan W, Calver DM. Aplasia of the optic chiasm and tracts with unifocal polymicrogyria in an otherwise healthy infant. J Pediatr Ophthalmol Strabismus 2002; 39: 187-189. 